\title{
Als Künstler und Kartograph im Heiligen Land (1851/1852). Die drei Palästina des C. W. M. van de Velde
}

Jutta Faehndrich (2021).

Berlín: Reimer, 223 páginas, 53 mapas e ilustraciones

ISBN 978-3-496-01645-8

\section{Emanuel Pfoh}

Consejo Nacional de Investigaciones Científicas y Técnicas / Universidad Nacional de La Plata, Argentina

El siglo XIX fue el siglo del “redescubrimiento" de Palestina para el Occidente cristiano en expansión imperial y colonial. El encomillado aplicado al término se justifica en la connotación que conlleva este re-descubrimiento: la civilización cristiana occidental siempre estuvo al tanto de dicho territorio en vista de que configuraba la Tierra Santa de la revelación divina y era el principal sitio hacia donde se peregrinaba, con mayor o menor intensidad, desde al menos los tiempos del Itinerarium Burdigalense del año 333. La diferencia que se produce unos 1400 años después de este hito textual, notablemente a partir de la ocupación e incursión napoléonica en Egipto y Siria de 1798-1801, es en efecto que este re-descubrimiento poseía ahora un cariz marcadamente científico, el cual se agregaba a pulsiones religiosas y de peregrinaje como una nueva capa de apropiación simbólica del territorio (cf., por ejemplo, Ben-Arieh, 1979; Silberman, 1982; Bar-Yosef, 2005). En este contexto, y en especial desde la pionera expedición topográfica de Edward Robinson y Eli Smith de 1838 en adelante (cf. Robinson y Smith, 1841), comenzaron a proliferar las incursiones europeas en Palestina, atendiendo a producir un conocimiento científico general del paisaje, más allá de las reminiscencias bíblicas, aunque en cercana relación con ellas. En este contexto es que encontramos la labor de Charles William Meredith van de Velde (1818-1898). Van de Velde, marino de origen neerlandés, visitó los actuales territorios de Siria, El Líbano, Israel y Palestina durante nueve meses, entre 1851 y 1852 , produciendo una serie de bellas ilustraciones y detallados mapas del territorio. La presente obra bajo reseña, escrita por Jutta Faehndrich, del LeibnizInstitut für Länderkunde de la Universidad de Leipzig (Alemania), ofrece una relativamente breve pero temáticamente densa indagación en la biografía académica de van de Velde en torno a dicho viaje.
Una Introducción (“Einführung”, pp. 13-21) ofrece el planteo general de la obra, encuadrando la investigación sobre Palestina realizada durante el siglo XIX -sintetizada en nuestro párrafo anterior-y poniendo de relieve la vinculación teológica (especialmente para el protestantismo) que tenía el conocimiento secular sobre la Tierra Santa, produciendo todo un campo de conocimiento que en Alemania fue denominado Palästinologie (cf. Goren, 2003; Kirchhoff, 2005). Uno de estos principales conocimientos seculares era el de la cartografía, que se desarrollaba a partir de intereses paralelos: lo geopolítico y militar y la rigurosidad en recuperar la topografía bíblica (cf. Goren, Faehndrich y Schelhaas, 2017). Aquí encontramos la publicación del Map of the Holy Land de van de Velde como parte de este conjunto de conocimientos científicos sobre Palestina.

El Capítulo 1 (“Biographisches und Familiäres: Die Person C. W. M. van de Velde”, pp. 23-35) proporciona detalles biográficos y de contexto general sobre el académico en los Países Bajos. En efecto, la inserción de esta potencia en el comercio mundial contribuyó al desarrollo de la carrera militar de van de Velde, pero también en su posterior performance como artista y en su labor humanitaria, en el marco del protestantismo evangélico profesado por esta figura. Así, en el Capítulo 2 (“Die Reise und ihr Bericht”, pp. 37-63) se detallan las condiciones de posibilidad para que individuos como van de Velde pudieran viajar a la considerada Tierra Santa: el mencionado redescubrimiento de la región en tiempos posnapoleónicos, la incursión de movimientos protestantes misioneros en Palestina, el conocimiento de las costumbres actuales de Palestina como manera de comprender mejor el mensaje bíblico, etc. Este espíritu de la época está muy bien 
representado por obras como The Land and the Book de William M. Thomson (1859) y Bible Lands de H. J. Van-Lennep (1875). En ellas -en verdad-se refleja el mundo intelectual que habitaba van de Velde, en el marco de la expansión imperial y colonial de las potencias europeas en la Palestina otomana.

El Capítulo 3 (“Die Bilder der Ferne”, pp. 65-85) describe la primera de las producciones artístico-científicas de van de Velde en su viaje: dibujos a color y esbozos de paisajes orientales. Estas ilustraciones representaban mucho más que un mero suvenir del viaje. En efecto, se correspondían a un primer esfuerzo por describir los paisajes de los escenarios bíblicos a través de tres motivos principales: lugares y ciudades, montañas y valles, y finalmente ríos, arroyos y costas marítimas (p. 71). Las ilustraciones no poseían, en verdad, una intención etnográfica en el sentido de una exhaustividad científica de la descripción del paisaje humano, pero sí estaban atravesadas por la esperable mirada orientalista del período, no menos en la distintiva perspectiva a la distancia de van de Velde. Pero, tal vez la mayor expresión de ello -tal como lo habían hecho Robinson y Smith unas tres décadas antes- haya sido la intención de identificar sitios bíblicos a través del significado contemporáneo de lugares con nombres árabes; la verificación arqueológica vendría a confirmar la identificación posteriormente (p. 73). Por su parte, el trasfondo de la producción del Map of the Holy Land por van de Velde es narrado en el Capítulo 4 (“Die Karte”, pp. 87-113). Sin duda, el impulso posnapoleónico por "conocer el Oriente" en sus diversas facetas científicas conllevó un desarrollo de la cartografía moderna de la región de parte de actores y poderes occidentales. Inseparable de ello fue el aspecto geopolítico y militar que tenía la cartografía de Oriente durante prácticamente todo el siglo XIX. La autora relata en este capítulo cómo van de Velde se involucró en un proceso académico colectivo, que incluyó a famosos cartógrafos y geógrafos europeos contemporáneos y también casas editoriales, que culminó con la producción de su mapa de la Tierra Santa, publicado en 1858 , y con una segunda edición actualizada en 1866.

En el Capítulo 5 ("Heiß, kalt oder wohltemperiert: Die drei Palästina des Luitenant van de Velde”, pp. 115-134) se expande la idea de las tres Palestinas de van de Velde a las que refiere el subtítulo de la obra. En efecto, estas tres Palestinas fueron expresadas por el académico neerlandés concretamente en ilustraciones, en reportes y en mapas. Tres soportes para tres versiones del mismo espacio físico. Este capítulo aborda estas versiones a través de su contextualización general en el mundo de las ideas filosóficas y geográficas sobre la representación de la realidad, y en particular sobre la atracción que la Tierra Santa producía en la expresión de la fe cristiana, especialmente, como ya notamos, en su vertiente protestante europea y americana durante el siglo XIX. Las tres versiones de Palestina referidas arriba tienen, además, un correlato con la simultaneidad de Palestina como espacio estético, mítico y teórico respectivamente. En primer lugar, la autora observa la dimensión religiosa del viaje a Tierra Santa -tanto de parte de van de Velde como de otros peregrinoscomo una construcción espacial de lo religioso, de su precisa manifestación. En cambio, la producción cartográfica, en su abstracción del espacio a través de la geometría, sirve a propósitos más mundanos como la dominación (colonial, etc.), y en este caso, un mapa de Tierra Santa iba precisamente más allá de guiar al eventual peregrino en su vagabundeo religioso para servir en última instancia como herramienta de conocimiento geopolítico. El aspecto mítico, anclado en la emoción y en la intersubjetividad con el paisaje (o mejor con la idea del mismo), por supuesto proviene de la evocación de un pasado religioso en un espacio del siglo XIX como lo era la Palestina otomana. En efecto, el viaje hacia esta Palestina permitía observar a los habitantes indígenas como "fósiles vivos" de un lejano pasado bíblico, de acuerdo con el orientalismo biblista que predominaba en la Europa de la segunda mitad del siglo XIX e inicios del XX (p. 130; cf. Kirchhoff, 2005: 256-312).

Una última y brevísima sección en este excepcional capítulo refiere a la técnica cartográfica y su pretensión moderna de representación racional del espacio tridimensional (pp. 132-134). Esta discusión, en rigor, da pie al siguiente Capítulo 6 ("Berufung, Glaube, Wissenschaft", pp. 135-142), en donde se reflexiona sobre los aspectos subjetivos que la disciplina de la cartografía habilitó durante el siglo XIX, período de su efectiva profesionalización. En primer lugar, la cartografía bíblica tiene como objetivo, en su descripción y representación racional del espacio, una razón teológica de encuadrar la revelación divina en el pasado y en el presente precisamente en coordenadas geográficas claras. En segundo lugar, y no obstante dicha razón 
teológica, el desarrollo moderno de la cartografía bíblica contribuyó a un conocimiento científico de Palestina como espacio geográfico.

Con el Capítulo 7 (“Fazit und Ausblick”, pp. 143-148) se presenta un sumario final sobre el contexto imperial y colonial en el que se desarrolló la cartografía bíblica, y en el cual se puede enmarcar también la multifacética obra de van de Velde producida luego de su viaje a Tierra Santa. Notas (pp. 149-167), referencias bibliográficas y pictóricas (pp. 169-186) y varias ilustraciones y mapas de van de Velde (pp. 193-223) cierran el volumen. La perspectiva pictórica desde un punto alto en la distancia, particularmente característica de estas bellas ilustraciones de paisajes y situaciones orientales producidas por van de Velde (cf. Cap. 3), es por cierto expresiva de los varios argumentos y análisis presentados en este libro.

En conclusión, esta obra representa una importante contribución a la historia intelectual y de biografías académicas, y la autora debe ser reconocida por ello. En verdad, el tratamiento a través de los sucesivos capítulos va más allá de una mera compilación de datos biográficos de van de Velde; por el contrario, cada capítulo contextualiza los momentos de la vida profesional del cartógrafo en un marco histórico, intelectual, ideológico y de conocimiento geográfico de Palestina. Esperamos que sea pronta la traducción de este volumen al inglés y al español para que se pueda alcanzar a un mayor número de lectores académicos, pero también al público general interesado. Asimismo, este volumen es sumamente relevante para completar el conocimiento sobre la historia de la investigación occidental de Palestina, en relación con la Biblia e igualmente en un marco de expansión europea (y luego americana) a través de Medio Oriente en tiempos modernos.

\section{Bibliografía}

"Bar-Yosef, E. (2005). The Holy Land in English Culture, 1799-1917: Palestine and the Question of Orientalism. Oxford: Clarendon Press.

"Ben-Arieh, Y. (1979). The Rediscovery of the Holy Land in the Nineteenth Century. Jerusalén: The Magnes Press.

"Goren, H. (2003). "Zieht und erforscht das Land". Die deutsche Palästinaforschung im 19. Jahrhundert. Gotinga: Wallstein.

"Goren, H., Faehndrich, J. y Schelhaas, B. (2017). Mapping the Holy Land: The Foundation of a Scientific Cartography of Palestine (Tauris Historical Geography 11). Londres: I. B. Tauris.

» Kirchhoff, M. (2005). Text zu Land. Palästina im wissenschaftlichen Diskurs 1865-1920. Gotinga: Vandenhoeck \& Ruprecht.

"Robinson, E. y Smith, E. (1841). Biblical Researches in Palestine, Mount Sinai and Arabia Petraea. A Journal of Travels in the Year 1838. Vols. I-II. Boston: Crocker and Brewster.

"Silberman, N. A. (1982). Digging for God and Country: Exploration, Archaeology, and the Secret Struggle for the Holy Land, 1799-1917. Nueva York: Doubleday.

»Thomson, W. M. (1859). The Land and the Book, or Biblical Illustrations Drawn from the Manners and Customs, the Scenes and Scenery of the Holy Land, 2 vols. Nueva York: Harper and Brothers.

»Van-Lennep, H. J. (1875). Bible Lands: Their Modern Customs and Manners Illustrative of Scripture. Nueva York: Harper \& Brothers. 
